\title{
FENOLOGIA, PRODUÇÃO E COMPOSIÇÃO DO MOSTO DA 'CABERNET SAUVIGNON' E 'TANNAT' EM CLIMA SUBTROPICAL'
}

\author{
ALESSANDRO JEFFERSON SATO ${ }^{2}$, BRUNO DA SILVA JUBILEU ${ }^{2}$, \\ ADRIANE MARINHO DE ASSIS ${ }^{3}$, SÉRGIO RUFFO ROBERTO ${ }^{4}$
}

RESUMO - O objetivo deste trabalho foi caracterizar a fenologia e a produção das videiras 'Cabernet Sauvignon' e 'Tannat' (Vitis vinifera L.), em clima subtropical, para a elaboração de vinho tinto. A área experimental foi instalada em uma propriedade comercial pertencente à Vinícola Intervin ${ }^{\circledR}$, em Maringá$\mathrm{PR}$, e as videiras foram conduzidas em latada sobre o 'IAC 766 Campinas', em espaçamento 4,0 x 1,5m. As avaliações tiveram início a partir das podas de frutificação, realizadas no fim do inverno, durante quatro safras consecutivas $(2003,2004,2005$ e 2006). Foram utilizadas 20 plantas representativas de cada variedade, sendo avaliada a duração em dias das principais fases fenológicas das videiras, bem como estimadas a produção por planta e a produtividade de cada variedade. A evolução de maturação das uvas foi determinada pela análise semanal do $\mathrm{pH}$, teor de sólidos solúveis totais (SST) e acidez titulável (AT) do mosto das bagas. A duração média do ciclo da videira 'Cabernet Sauvignon' foi de 130,3 dias, enquanto da 'Tannat' foi de 131,3. As estimativas médias da produção por planta e da produtividade foram, respectivamente, de 4,5 kg e 8,9 t ha-1 para a uva 'Cabernet Sauvignon' e 7,3 $\mathrm{kg}$ e 12,1 tha-1 para a 'Tannat'. Os teores médios de $\mathrm{pH}$, SST e AT foram, respectivamente, de 3,$3 ; 14,5^{\circ}$ Brix e $1,1 \%$ de ácido tartárico para a uva 'Cabernet Sauvignon', e 3,$3 ; 17,7^{\circ}$ Brix e $1,1 \%$ de ácido tartárico para a 'Tannat'.

Termos para indexação: Vitis vinifera, poda, ciclo, maturação, vinho.

\section{PHENOLOGY, PRODUCTION AND MUST COMPOUNDS OF 'CABERNET SAUVIGNON'AND 'TANNAT’ GRAPEVINES IN SUBTROPICAL CLIMATE}

\begin{abstract}
The objective of this study was to characterize the phenology and the production of 'Cabernet Sauvignon' and 'Tannat' (Vitis vinifera L.) grapes produced in a subtropical climate for red winemaking. The experimental area was located in a commercial vineyard belonging to the Intervin ${ }^{\circledR}$ Winery, in Maringá, PR. The grapevines were trained in a pergola system in a $4.0 \times 1.5 \mathrm{~m}$ spacing, grafted on 'IAC 766 Campinas' rootstock. The evaluations started from the pruning held in late winter during four crops $(2003,2004,2005$ and 2006). For assessments, 20 representative grapevines were used of each variety. The phenology of the plants was evaluated as the duration in days, as well it was estimated the production and productivity of each variety. The ripening development was determined by the analysis of berries chemical characteristics, such as $\mathrm{pH}$, total soluble solids (TSS) and titratable acidity (TA). It was determined that the average cycle of 'Cabernet Sauvignon' was 130.3 days, while the 'Tannat' was 131.3. The production per plant and productivity average estimates were $4.5 \mathrm{~kg}$ and $8.9 \mathrm{tha}^{-1}$, respectively for 'Cabernet Sauvignon' and $7.3 \mathrm{~kg}$ and $12.1 \mathrm{t} \mathrm{ha}^{-1}$, respectively for 'Tannat'. The mean levels of $\mathrm{pH}$, TSS and TA were $3.3,14.5^{\circ}$ Brix and $1.1 \%$ tartaric acid respectively, for 'Cabernet Sauvignon', and $3.3,17.7^{\circ}$ Brix and $1.1 \%$ tartaric acid respectively for 'Tannat'. Index terms: Vitis vinifera, pruning, cycle, maturation, wine.
\end{abstract}

\footnotetext{
${ }^{1}$ (Trabalho 121-10). Recebido em: 11-05-2010. Aceito para publicação em: 19-10-2010. Projeto financiado pelo CNPq, processo $n^{\circ}$ 302977/2007-4

${ }^{2}$ Eng. Agr., Dr., Bolsista de Pós-Doutoramento - PNPD/CAPES. Fitotecnia. Universidade Estadual do Centro-Oeste, Rua Simeão Varella de Sá, 03. 85040-080, Guarapuava, PR. E-mail: ajsato82@yahoo.com.br

${ }^{3}$ Eng. Agr., Dra., Bolsista de Pós-Doutoramento - PNPD- CAPES. Fitotecnia, Universidade Estadual de Londrina, CP 6001, 86051990, Londrina-PR. E-mail: agroagri@ig.com.br

${ }^{4}$ Eng. Agr., Dr., Professor Associado, Departamento de Agronomia/Fitotecnia, Universidade Estadual de Londrina, Bolsista do CNPq, CP 6001, 86051-990. E-mail: sroberto@uel.br
} 


\section{INTRODUÇÃO}

A viticultura é um importante segmento da fruticultura brasileira e está presente em diversos Estados, como o Rio Grande do Sul, São Paulo, Paraná, Pernambuco, Bahia, entre outros (MOURA et al., 2009).

No Paraná, a videira ocupa uma área de aproximadamente 6 mil hectares, com produção média acima de 100 mil toneladas (IBGE, 2010). O Estado caracteriza-se pela produção de uvas finas de mesa, cultivadas principalmente na região Norte com duas safras anuais, uma regular, com a colheita realizada nos meses de dezembro-janeiro e a outra fora de época, com a obtenção de uvas em junho-julho. Na região Sul, a viticultura está presente em menor escala com o cultivo de uvas americanas ou híbridas, destinadas principalmente ao processamento (KISHINO; ROBERTO, 2007). Recentemente, o oeste do Estado iniciou o cultivo de uvas para vinificação, obtendo inclusive vinhos premiados internacionalmente (JUBILEU et al., 2010).

No Brasil, várias regiões produtoras passaram a diversificar sua produção, uma vez que a demanda por uvas destinadas ao processamento de vinhos e sucos aumentou significativamente. A comercialização brasileira de vinhos, em 2009, foi de 189,9 milhões de litros, enquanto em 2008 este valor foi de 168,4 milhões de litros, o que representa aumento de $12,8 \%$. Dentre os tipos de vinhos comercializados, o tinto foi o que teve maior aumento na demanda, com crescimento de $16,3 \%$ em 2009 , o que corresponde à comercialização de 10,7 milhões de litros (IBRAVIN, 2009). Este crescimento no mercado vitivinícola está relacionado às constantes divulgações sobre os efeitos benéficos que o consumo moderado de vinho, principalmente o tinto, pode causar à saúde (MENEZES, 2005).

O principal produtor nacional de uvas destinadas ao processamento é o Rio Grande do Sul, sendo responsável por $90 \%$ de toda a produção de vinhos brasileiros, entretanto novas regiões têm surgido como opção para este mercado, como o Vale do São Francisco, Santa Catarina e, recentemente, o Paraná, onde foram realizados grandes investimentos com a implantação de fábricas de sucos de uva concentrado, além de vinícolas de pequeno e médio portes (MELLO, 2007; JUBILEU et al., 2010). Dentre as videiras finas cultivadas nestas novas regiões, destacam-se a 'Cabernet Sauvignon' e a 'Tannat' (Vitis vinifera L.), ambas de origem francesa (RIZZON; MIELE, 2004).

A 'Cabernet Sauvignon' passou a ser cultivada em maior escala no Brasil somente a partir da década de 80 , tornando-se, assim, uma importante uva para a vinificação no País (LEÃO et al., 2009). Atualmente, diversas regiões têm buscado informações para o cultivo desta uva, tendo em vista que os vinhos elaborados com esta variedade são bem aceitos pelo mercado consumidor.

A uva 'Tannat', assim como a 'Cabernet Sauvignon', passou a ser cultivada com maior interesse comercial no País somente a partir da década de 80 e, atualmente, é uma uva cultivada para a elaboração de vinhos tintos utilizados para corte, bem como varietais, com bom aporte de cor, extrato seco e teor alcoólico (LEÃO et al., 2009).

Quando se deseja implantar um vinhedo com novas variedades em uma região onde o seu cultivo é pouco conhecido, é necessário que se avalie seu comportamento fenológico e produtivo em função das condições edafoclimáticas locais, pois o desempenho das videiras varia em função da interação do genótipo com as condições climáticas (LEÃO; SILVA, 2003). Características como a temperatura e a precipitação podem influenciar diretamente no comportamento fenológico das videiras, bem como a amplitude térmica e o tipo de solo têm influência sobre as características físico-químicas das uvas (KISHINO; MARUR, 2007).

O trabalho teve como objetivo caracterizar a fenologia, os aspectos produtivos e a composição das uvas da 'Cabernet Sauvignon'e da 'Tannat' destinadas à vinificação no norte do Paraná.

\section{MATERIAL E MÉTODOS}

O experimento foi conduzido em dois vinhedos comerciais de 'Cabernet Sauvignon' e 'Tannat' (Vitis vinifera L.), enxertadas sobre o portaenxerto IAC 766 'Campinas', conduzidas em latada, em espaçamento de 4,0 x 1,5 m, implantadas em julho de 2001, pertencente à Vinícola Intervin ${ }^{\circledR}$, localizada em Maringá-PR $\left(23^{\circ} 25^{\prime} \mathrm{S}, 5^{\circ} 57^{\prime} \mathrm{W}\right)$. Os indicadores climáticos médios da região são de $1.600 \mathrm{~mm}$ de precipitação anual, temperatura média de $20,7^{\circ} \mathrm{C}$ e $73 \%$ de umidade relativa, de clima subtropical, com temperatura média dos meses mais frios (junho e julho) em torno de $16,7^{\circ} \mathrm{C}$ (BORROZINO, 2004).

O solo desta região é classificado como Latossolo Vermelho distrófico. Com relação à adubação, durante o repouso vegetativo, foram incorporados ao solo cerca de $60 \mathrm{t} \mathrm{ha}^{-1}$ de esterco bovino e, logo após a poda de produção, realizou-se a incorporação de $24 \mathrm{~kg} \mathrm{ha}^{-1}$ de $\mathrm{N}$ e $100 \mathrm{~kg} \cdot \mathrm{ha}^{-1}$ de $\mathrm{P}_{2} \mathrm{O}_{5}$. Aproximadamente 30 dias após o surgimento das brotações, foram incorporados cerca de $19 \mathrm{~kg} \cdot \mathrm{ha}^{-1}$ de $\mathrm{N}$ e $100 \mathrm{~kg} \cdot \mathrm{ha}^{-1}$ de $\mathrm{P}_{2} \mathrm{O}_{5}$. Não foram realizadas 
adubações com potássio, tendo em vista que a área experimental apresentava teores adequados deste nutriente para o cultivo de uvas.

As avaliações da duração do ciclo fenológico e das características produtivas das videiras foram realizadas em quatro safras consecutivas $(2003,2004$, 2005 e 2006). O delineamento experimental utilizado foi o inteiramente casualizado, com vinte repetições.

As podas de frutificação foram realizadas logo após o fim do inverno, quando ocorreu o início do inchamento das gemas, e, em seguida, foi aplicado o regulador de crescimento cianamida hidrogenada a 2,5\% para a quebra da dormência das gemas das videiras, com o objetivo de obter brotação uniforme das mesmas. As podas foram realizadas deixando-se quatro ou cinco gemas por vara.

Para o acompanhamento dos estádios fenológicos, foram etiquetados dois ramos de cada planta. Foi avaliada nestes ramos, por meio de observações visuais, a duração em dias dos seguintes estágios, a partir da poda de frutificação (PO), segundo a classificação baseada em Baggiolini (1952) e Baillod e Baggiolini (1993):

(a) Gema-algodão (GA): quando $50 \%$ das gemas atingiram o segundo estádio de desenvolvimento da videira, ou seja, quando as escamas se romperam e apareceu a plumagem; (b) Brotação (BR): quando $50 \%$ das gemas atingiram o quarto estádio, ou seja, a saída das folhas; (c) Aparecimento da inflorescência (AI): quando 50\% dos ramos apresentaram inflorescência, quando os cachos eram visíveis, embora rudimentares; (d) Florescimento (FL): quando $50 \%$ das flores se encontraram abertas (florescimento propriamente dito com flores visíveis); (e) Início da maturação (IM): quando $50 \%$ das bagas mudaram de coloração, isto é, as bagas com coloração avermelhada e o momento em que estas iniciaram o amolecimento; (f) Colheita (CO): momento em que $100 \%$ das bagas apresentaram coloração intensa, com o teor de sólidos solúveis totais o mais elevado possível.

A avaliação das características produtivas consistiu em análises semanais de $\mathrm{pH}$, teor de sólidos solúveis (SST) e acidez titulável (AT) do mosto das bagas, a partir do início da maturação até sete dias após a colheita. Para tais avaliações, foram coletadas 300 bagas, subdivididas manualmente em dez amostras de 30 bagas de cada variedade. As bagas foram trituradas, e o mosto, previamente filtrado em algodão, sendo que o $\mathrm{pH}$ foi obtido por peagâmetro digital. O teor de SST foi determinado em refratômetro de bancada, com compensação automática de temperatura (Kruss Optronic, Modelo DR 301-95, Alemanha) e o resultado expresso em
${ }^{\circ}$ Brix (INSTITUTO ADOLFO LUTZ, 1985). A determinação da AT foi realizada por titulação do mosto, com solução padronizada de $\mathrm{NaOH} 0,1 \mathrm{~N}$ em titulador potenciométrico digital, com $\mathrm{pH}$ final de titulação ajustado para 8,2 (Schott Gerate, Modelo Tritoline Easy, Alemanha) e o resultado expresso em \% de ácido tartárico (INSTITUTO ADOLFO LUTZ, 1985).

Por ocasião da colheita de cada safra, avaliouse o número de cachos por planta e posteriormente retiraram-se cinco cachos de cada planta nos quais se avaliaram: a massa $(\mathrm{g})$ das bagas em balança digital, o diâmetro das bagas $(\mathrm{mm})$ com paquímetro digital e a massa dos cachos ( $\mathrm{g}$ ) em balança digital. Em função destes resultados e da densidade de plantas por hectare, estimaram-se a produção por planta $(\mathrm{kg}$ planta $\left.{ }^{-1}\right)$ e a produtividade $\left(\mathrm{t} \mathrm{ha}^{-1}\right)$.

\section{RESULTADOS E DISCUSSÃO}

O ciclo total, ou seja, o período entre a PO-CO da 'Cabernet Sauvignon', teve duração média de 130,3 dias, enquanto a dos subperíodos PO-GA; GA-BR; BR-AI; AI-FL; FL-IM e IMCO foram em média 11,$8 ; 4 ; 3 ; 22,5 ; 56,2$ e 32,5 dias, respectivamente (Tabela 1). Para a 'Tannat', observou-se que o ciclo total foi em média 131,3 dias, e os subperíodos PO-GA; GA-BR; BR-AI; AI-FL; FL-IM e IM-CO foram em média de 12; 4,5; 3,$5 ; 21 ; 51,3$ e 39 dias, respectivamente.

Em trabalho realizado na região Serra Gaúcha, onde a temperatura média anual é em torno de $17^{\circ} \mathrm{C}$, Mandelli et al. (2004) e Kuhn et al. (1996) relatam que a 'Cabernet Sauvignon' apresenta ciclo de aproximadamente 168 dias. Na região de Bourdeaux, França (temperatura média anual de $13^{\circ} \mathrm{C}$ ), segundo Jones e Davis (2000), o ciclo da 'Cabernet Sauvignon' é de, aproximadamente, 193 dias. No entanto, Lima et al. (2003) verificaram que a 'Cabernet Sauvignon' cultivada na região do Vale do Submédio do São Francisco, onde a temperatura média durante anual é em torno de $25,6^{\circ} \mathrm{C}$, apresenta em média ciclo de 131 dias, semelhante ao observado no presente trabalho.

Em relação à cultivar Tannat, verificou-se neste trabalho que o seu ciclo, 131,3 dias em média, é inferior ao observado em outras regiões produtoras. Souza et al. (2002), em Caldas-MG (tempeartura média anual de $24,5{ }^{\circ} \mathrm{C}$ ), verificaram que o ciclo desta uva é em média de 160 dias, enquanto Kuhn et al. (1996) verificaram que esta videira apresenta ciclo de 170 dias na Serra Gaúcha. Para as condições do Submédio do Vale do São Francisco, Lima et al. (2003) constataram que a 'Tannat' apresenta em mé- 
dia ciclo de 118 dias, sendo inferior ao observado nas demais regiões produtoras, inclusive aos resultados obtidos neste trabalho.

Considerando-se que durante a safra no norte do Paraná a temperatura média $\left(20,7^{\circ} \mathrm{C}\right)$ é mais elevada do que em regiões como a Serra Gaúcha (RS), Caldas (MG) e Bordeaux (França) (SANTOS et al., 2007), e menor quando comparadas a regiões como o Vale do São Francisco, as diferenças na duração do ciclo da 'Cabernet Sauvignon' e da 'Tannat', observadas neste trabalho em relação às demais regiões, corroboram Kishino e Marur (2007), que relatam que a duração do ciclo produtivo da videira pode variar entre outros motivos, em função da temperatura do ar.

Além das condições climáticas, como a temperatura, outro fator que pode ter influenciado na redução do ciclo das videiras estudadas é a utilização do IAC 766 'Campinas' como porta-enxerto. Embora esteja muito bem adaptado às condições norte paranaenses (KISHINO et al., 2007), é conhecida sua característica de imprimir maior vigor às cultivares copa nele enxertadas, o que pode ter influência direta na qualidade dos vinhos. Associado ao porta-enxerto, as adubações realizadas durante as safras permitiram que as videiras se desenvolvessem de forma bastante vigorosa e consequentemente ter contribuído para a redução da duração do ciclo das videiras.

Com base nas diferenças observadas na duração do ciclo em diferentes locais, considera-se que o conhecimento do seu comportamento fenológico é uma exigência da viticultura moderna, uma vez que possibilita a racionalização e otimização das práticas culturais, indispensáveis para o cultivo (MANDELLI et al., 2004). Desta forma, é possível programar datas de poda, quebra de dormência, aplicação de defensivos, colheita e também otimizar o emprego da mão de obra nas diversas fases do ciclo, reduzindo os tratos fitossanitários e os custos de produção (MURAKAMI et al., 2002).

Em relação à evolução da maturação, a 'Cabernet Sauvignon' e a 'Tannat' apresentaram comportamento progressivo para as variáveis $\mathrm{pH}$ e SST (Figura 1), sendo que o pH no início da maturação foi de 2,7 e no momento da colheita elevou-se para 3,3 para ambas as uvas, o que se encontra dentro da faixa considerada ideal para a elaboração de vinhos, pois de acordo com Rizzon e Miele (2002), na Serra Gaúcha, o ideal é que o mosto das uvas apresente $\mathrm{pH}$ de até 3,3.

Para o teor de sólidos solúveis totais (SST), a 'Cabernet Sauvignon' apresentou, no início da maturação, $5,3^{\circ}$ Brix e, no momento da colheita, $14,5^{\circ}$ Brix (Figura 1). No entanto, no período de 07 dias após a colheita, observou-se que o teor de SST se elevou para $15,7^{\circ}$ Brix. O mesmo comportamento foi observado para a videira 'Tannat', que apresentou inicialmente teor de SST de 4, $4^{\circ}$ Brix e, no momento da colheita, $17,7^{\circ}$ Brix (Figura 1), sendo que, no período de 07 dias após a colheita, o teor de SST continuou evoluindo progressivamente até atingir $18,1^{\circ} \mathrm{Brix}$. A diferença nos teores de SST entre as uvas pode estar relacionada ao maior número de cachos da 'Cabernet Sauvignon' em relação à 'Tannat', pois desta forma o equilíbrio fonte-dreno foi melhor nesta última uva.

Rizzon e Miele (2002) relataram que o comportamento da evolução da maturação da uva 'Cabernet Sauvignon' cultivada na Serra Gaúcha, onde apresenta ganho acelerado de SST durante o período de maturação, com teores máximos próximo à colheita. Lima et al. (2003) verificaram que, nas condições do Vale do São Francisco, essa uva apresenta ganho mais acentuado no acúmulo de SST nos dez primeiros dias do início da maturação, e após esse período, o acúmulo é gradual, até chegar aproximadamente a $17^{\circ}$ Brix.

Para a videira 'Tannat', assim como ocorre com a 'Cabernet Sauvignon', resultados semelhantes aos obtidos neste trabalho foram encontrados por Rizzon e Miele (2004) na Serra Gaúcha, os quais observaram que o maior acúmulo de SST ocorre a partir da terceira semana após o início do período de maturação, e continua evoluindo progressivamente até o período da colheita, atingindo em média $18,6^{\circ}$ Brix.

Os resultados encontrados neste trabalho estão de acordo com o descrito por Blouim e Guimberteau (2004), que relatam que durante a fase de desenvolvimento da baga, o açúcar produzido é direcionado às folhas, ao desenvolvimento da planta e do fruto, sobretudo para o crescimento e maturação da semente. Somente a partir da fase de início da maturação é que ocorre uma modificação metabólica na translocação do açúcar, ocasionando, desta forma, um grande acúmulo deste componente nas bagas.

Vale ressaltar que o conhecimento do comportamento evolutivo do teor de SST durante a maturação das uvas é muito importante, pois este parâmetro é fundamental na fase de elaboração dos vinhos, tendo em vista que, para cada $1^{\circ} \mathrm{GL}$ de álcool, é necessário $1,8^{\circ}$ Brix no mosto. De acordo com a legislação brasileira, os vinhos devem apresentar graduação alcoólica entre 10 e $13^{\circ}$ GL (GUERRA; ZANUS, 2003), portanto, quando se deseja obter vinhos de qualidade, é fundamental saber qual o potencial de acúmulo de SST das uvas que se pretende utilizar.

Embora se tenha observado que, no presente trabalho, o teor de SST das uvas 'Cabernet Sauvignon' 
e 'Tannat' continuou evoluindo progressivamente mesmo após a definição das datas de colheita, as mesmas foram realizadas nos momentos mais adequados, pois essa decisão varia em função de diversos fatores, como a integridade física dos cachos, a ocorrência de insetos e de doenças, as condições climáticas, sobretudo precipitação, e as demais características químicas das bagas (GUERRA, 2003).

De acordo com os valores de SST observados neste trabalho, verifica-se que a uva 'Tannat' apresenta maior potencial para a elaboração de vinhos quando comparada à 'Cabernet Sauvignon', entretanto as médias dos quatro anos de avaliações indicam a necessidade da chaptalização do mosto para a obtenção de vinhos com graduação alcoólica dentro dos padrões exigidos pela legislação brasileira.

Para a evolução do teor de acidez titulável (Figura 1), o comportamento foi inverso à evolução dos teores de $\mathrm{pH}$ e SST, em ambas as uvas, verificando-se que a AT na colheita foi em média de 1,1\% de ácido tartárico. Ressalta-se que, embora o teor de AT tenha sido o mesmo para a 'Cabernet Sauvignon' e para a 'Tannat', o teor de SST foi maior nesta última uva, o que favorece a composição qualitativa do seu mosto, pois se deve atentar para a interação entre os aspectos químicos e não somente para os seus valores individuais.

Rizzon e Miele (2002) encontraram resultados semelhantes para a 'Cabernet Sauvignon' cultivada na Serra Gaúcha, onde esta uva apresenta AT de $0,85 \%$ ao final da maturação. O mesmo foi verificado por Lima et al. (2003), que apontaram que, na região do Vale do São Francisco, a uva 'Cabernet Sauvignon' apresenta, ao final da maturação, $0,8 \%$ de AT. Para a videira 'Tannat' cultivada na Serra Gaúcha, Rizzon e Miele (2004) observaram comportamento semelhante, com AT elevada no início da maturação e queda acentuada até o momento da colheita.

Segundo Blouim e Guimberteau (2004), os principais ácidos das videiras (tartárico e málico) são sintetizados pelas folhas e pelas bagas ainda verdes; portanto, no início da maturação, as bagas apresentam elevado teor de AT. Porém, com a evolução da maturação, a demanda por energia é maior, e para suprir essa necessidade, os ácidos são utilizados como fonte de energia. Além disso, fatores como a diluição dos ácidos orgânicos, devido ao aumento do tamanho da baga, a migração de bases e a consequente salificação dos ácidos orgânicos também contribuem para a redução no teor de AT (RUFFNET et al., 1983).

Destaca-se que, no norte do Paraná, o portaenxerto utilizado (IAC 766 'Campinas') propicia maior vigor às plantas e ciclo mais precoce em relação às demais regiões produtoras, principalmente a fase do subperíodo IM-CO, o que pode ter influenciado no acúmulo de SST e na degradação de AT. Além disso, o sistema de condução utilizado (latada) pode ter influência nestes aspectos, tendo em vista que, em sistemas de condução como a espaldeira, os cachos ficam mais expostos à luminosidade, fator este fundamental no acúmulo de SST e degradação da AT (BLOUIN; GUIMBERTEAU, 2004).

Em relação aos aspectos físicos das uvas, observa-se que a 'Cabernet Sauvignon' apresentou no momento da colheita, em média, massa e diâmetro das bagas de $1,2 \mathrm{~g}$ e $12,8 \mathrm{~mm}$, respectivamente, enquanto para a 'Tannat', as mesmas variáveis foram em média 1,5 g e 12,1 mm, respectivamente (Tabela 2). Resultados semelhantes foram obtidos por Rizzon e Miele (2002) no Rio Grande do Sul, Lima et al. (2003) no Vale do São Francisco e Jones e Davis (2000) em Bordeaux, França.

Para os aspectos de produção, verifica-se que o número de cachos por planta, massa e comprimento dos cachos, produção e produtividade da cultivar Cabernet Sauvignon foi de 41,3 cachos por planta; $110 \mathrm{~g} ; 13,5 \mathrm{~cm} ; 4,5 \mathrm{~kg}$ e $8,9 \mathrm{t} \mathrm{ha}^{-1}$, respectivamente (Tabela 2). As mesmas variáveis para a uva 'Tannat' apresentaram valores superiores em relação ao observado para a 'Cabernet Sauvignon', de 29,9 cachos por planta; $200 \mathrm{~g}$; 12,1 cm; 7,3 kg e 12,1 $\mathrm{t} \mathrm{ha}^{-1}$, respectivamente.

Rizzon e Miele (2002) relatam que, para as condições da Serra Gaúcha, os cachos de 'Cabernet Sauvignon' apresentaram massa de $140 \mathrm{~g}$, enquanto no Vale do São Francisco, Lima et al. (2003) apontam que, para a mesma variedade, os cachos apresentam massa média de $80 \mathrm{~g}$. Observa-se que os cachos dessa uva, neste trabalho, possuem massa inferior à encontrada na Serra Gaúcha, mas superior à do Vale do São Francisco. Para a 'Tannat', resultados semelhantes aos obtidos neste trabalho foram verificados por Rizzon e Miele (2004) na Serra Gaúcha e por Lima et al. (2003) no Vale do São Francisco, que verificram que a massa média dos cachos, em ambas as regiões, é em média de $210 \mathrm{~g}$.

Em relação à produtividade e produção, Souza et al. (2002) determinaram que a 'Cabernet Sauvignon' cultivada na região de Caldas, Sul de Minas Gerais, apresentou produtividade de 11,7 t ha ${ }^{-1}$ e produção de 4,7 kg planta-1 ${ }^{-1}$ Na região da Campanha Gaúcha, Brunetto et al. (2007) observaram produtividade de $15,5 \mathrm{t} \mathrm{ha}^{-1}$ e produção de $13,1 \mathrm{~kg}$ planta $^{-1}$. Em relação à videira 'Tannat', Souza et al. (2002) descrevem que, quando cultivada em Caldas$\mathrm{MG}$, apresenta produção e produtividade de $2,58 \mathrm{~kg}$ planta $^{-1}$ e $6,25 \mathrm{t} \mathrm{ha}^{-1}$, respectivamente.

As diferenças na produtividade das uvas 
'Cabernet Sauvignon' e 'Tannat', observadas entre as regiões produtoras, podem estar relacionadas a diversos fatores, no entanto destaca-se que, neste trabalho, o sistema de condução utilizado foi a latada em espaçamento de $4,0 \times 1,5 \mathrm{~m}$, enquanto nas demais regiões o sistema de condução é a espaldeira, com espaçamento que varia de $2,5 \times 1,5 \mathrm{~m}$ até 2,0 x $1,0 \mathrm{~m}$. Outro fator que pode ter influenciado é o porta-enxerto utilizado, tendo em vista que, nas demais regiões produtoras, utilizam-se cultivares que imprimem menor vigor vegetativo às copas, como, por exemplo, o 1103 Paulsen.

Tendo em vista que este trabalho foi realizado em safra tradicional, ou seja, em um período no qual podem ocorrer altas precipitações na fase de maturação das uvas e que o porta-enxerto utilizado imprime grande vigor às cultivares copa, considerase que a utilização de diferentes técnicas, como o deslocamento da produção para a safra de época, a realização do raleio de cachos e a utilização de sistemas de condução, como a espaldeira, podem contribuir para a melhoria na qualidade das uvas destinadas à vinificação no norte do Paraná.

TABELA 1 - Duração em dias dos estádios fenológicos das videiras 'Cabernet Sauvignon' e 'Tannat' produzidas em clima subtropical, nas safras de 2003, 2004, 2005 e 2006.

\begin{tabular}{ccc}
\hline Subperíodo & 'Cabernet Sauvignon' & 'Tannat' \\
\hline PO-GA & $11,8 \pm 1,9$ & $12,0 \pm 1,8$ \\
GA-BR & $4,0 \pm 0,8$ & $4,5 \pm 1,7$ \\
BR-AI & $3,0 \pm 0,8$ & $3,5 \pm 0,6$ \\
AI-FL & $22,5 \pm 1,3$ & $21,0 \pm 2,6$ \\
FL-IM & $56,5 \pm 4,7$ & $51,3 \pm 6,2$ \\
IM-CO & $32,5 \pm 1,3$ & $39,0 \pm 4,2$ \\
PO-CO & $130,3 \pm 2,9$ & $131,3 \pm 11,3$ \\
\hline
\end{tabular}

(PO): Poda; (GA): Gema-algodão; (BR): Brotação; (AI): Aparecimento da Inflorescência; (FL): Florescimento; (IM): Início da Maturação; (CO): Colheita.

TABELA 2 - Produção e seus componentes em videiras 'Cabernet Sauvignon' e 'Tannat' cultivadas em clima subtropical, nas safras de 2003, 2004, 2005 e 2006.

\begin{tabular}{lcc}
\hline & 'Cabernet Sauvignon' & 'Tannat' \\
\hline Massa das bagas (g) & $1,2 \pm 0,1$ & $1,5 \pm 0,3$ \\
Diâmetro das bagas (mm) & $12,8 \pm 1,8$ & $12,1 \pm 1,2$ \\
$\mathrm{~N}^{\text {o }}$ cachos/planta (un.) & $41,3 \pm 25,3$ & $29,9 \pm 12,7$ \\
Massa dos cachos (g) & $110,0 \pm 10,0$ & $200,0 \pm 20,0$ \\
Comprimento dos cachos (cm) & $13,5 \pm 3,6$ & $12,1 \pm 2,3$ \\
Produção (kg planta $\left.{ }^{-1}\right)^{\mathrm{a} /}$ & $4,5 \pm 3,3$ & $7,3 \pm 4,8$ \\
Produtividade $\left(\mathrm{t} \mathrm{ha}^{-1}\right)^{\mathrm{b} /}$ & $8,9 \pm 5,5$ & $12,1 \pm 8$ \\
\hline
\end{tabular}

\footnotetext{
${ }^{a}$ : Estimativa em função do número de cachos/planta e da massa dos cachos.

${ }^{\mathrm{b} /}$ : Estimativa em função da produção por planta e do número de plantas por hectare.
} 

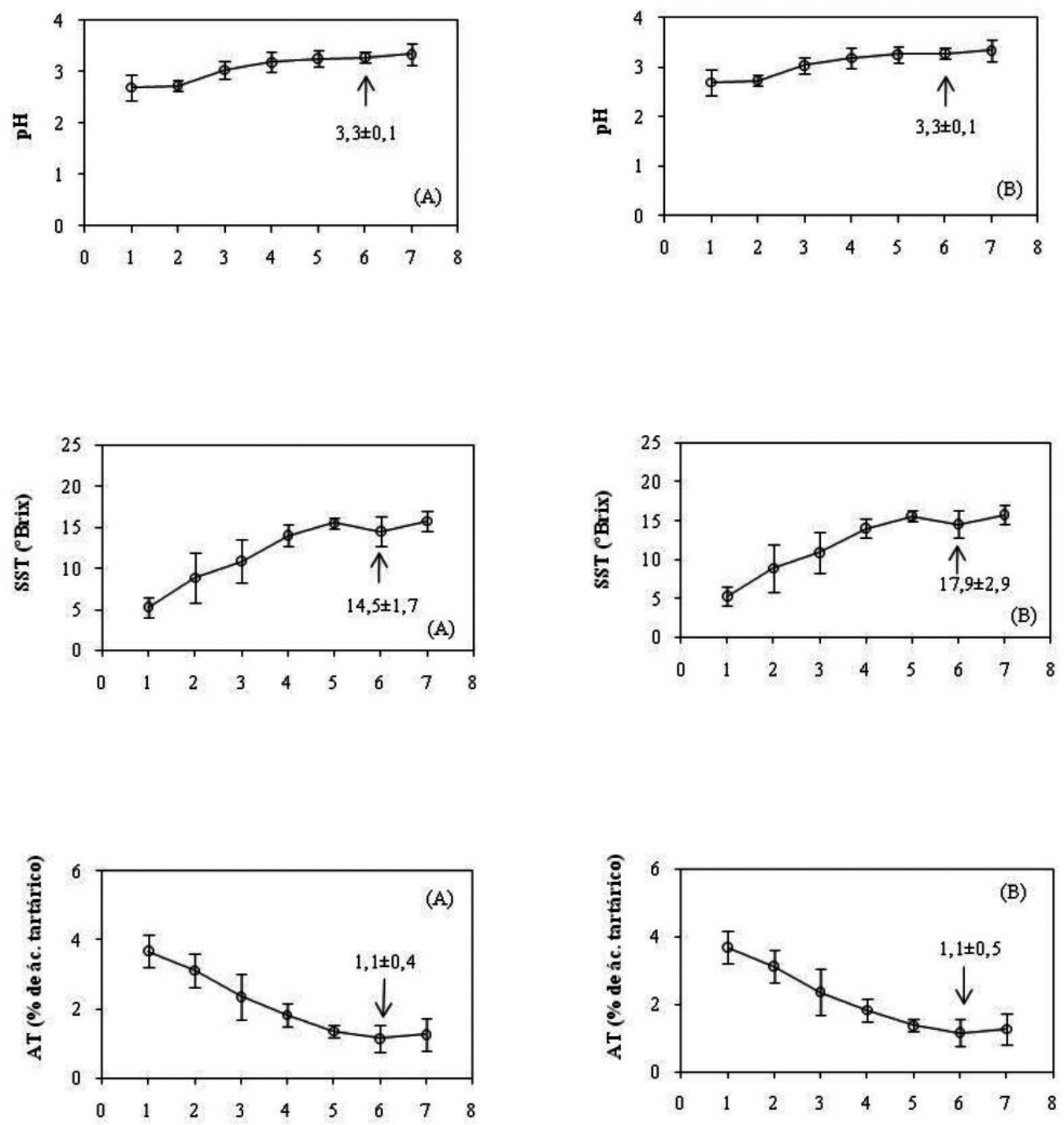

FIGURA 1 - Evolução dos teores de pH, sólidos solúveis totais (SST), acidez titulável (AT), do mosto das uvas 'Cabernet Sauvignon'(A) e 'Tannat' (B) produzidas em clima subtropical, nas safras de 2003, 2004, 2005 e 2006. As setas indicam o momento da colheita.

\section{CONCLUSÕES}

A duração média do ciclo da videira 'Cabernet Sauvignon'é de 130,3 dias, enquanto da 'Tannat' é de 131,3. As estimativas médias da produção por planta e a produtividade são de $4,5 \mathrm{~kg}$ e $8,9 \mathrm{t} \mathrm{ha}^{-1}$ para a uva 'Cabernet Sauvignon' e 7,3 kg e 12,1 t ha $^{-1}$ para a 'Tannat'. Os teores médios de $\mathrm{pH}, \mathrm{SST}$ e AT são de 3,$3 ; 14,5^{\circ}$ Brix e $1,1 \%$ de ácido tartárico, respectivamente, para a uva 'Cabernet Sauvignon', e 3,$3 ; 17,7^{\circ}$ Brix e $1,1 \%$ de ácido tartárico, respectivamente, para a 'Tannat'.

\section{REFERÊNCIAS}

BAGGIOLINI, M. Lês stades repères dans lê developpement anual de la vigne. Revue Romande: Revue mensuelle d agriculture, de viticulture et d arboriculture, Lausanne, v.8, p.4-5, 1952.

BAILLOD, M.; BAGGIOLINI, M. Lês stades repères de la vigne. Revue Suisse Viticulture Horticulture, Croft, v. 25, n.1, p.7-9, 1993. 
BORROZINO, E. Média dos dados climáticos da região Norte do Paraná. Londrina: IAPAR, 2004. Disponível em: <www.iapar.br>. Acesso em: 15 mar. 2010.

BLOUIN, J.; GUIMBERTEAU, G. Maduracion y madurez de la uva. Madrid: Ediciones MundiPrensa, 2004. 151 p.

BRUNETTO, G.; CERETTA, C. A.; KAMINSKI, J.; MELLO G.W.B.; LOURENZI, C.R.; FURLANETTO, V.; MORAES, A. Aplicação de nitrogênio em videiras na Campanha Gaúcha: produtividade e características químicas do mosto da uva. Ciência Rural, Santa Maria, v.37, n.2, p. 389-393, 2007.

GUERRA, C.C. Uvas americanas e híbridas para processamento em clima temperado, 2003. Disponível em: $<$ http://sistemasdeproducao.cnptia. embrapa.br/FontesHTML/Uva/UvaAmericanaHibridaClimaTemperado/colheita.htm $>$ Acesso em: 15 mar. 2010.

GUERRA, C.C; ZANUS, M.C. Uvas viníferas para processamento em região de clima temperado, 2003. Disponível em: $<$ http://www.cnpuv.embrapa. $\mathrm{br} /$ publica/sprod/UvasViniferasRegioesClimaTemperado/colheita.htm>. Acesso em: 11 mar. 2010.

IBRAVIN - Instituto Brasileiro do Vinho. Venda de vinhos no Brasil aumenta $\mathbf{1 2 , 7 \%}$ de janeiro a outubro de 2009. Disponível em: $<$ http://www. ibravin.com.br/int_noticias.php?id=343\&tipo $=\mathrm{N}>$. Acesso em: 30 mar. 2010.

INSTITUTO ADOLFO LUTZ. Normas analíticas do Instituto Adolfo Lutz: métodos químicos e físicos para análise dos alimentos. 3. ed. São Paulo: Instituto Adolfo Lutz, 1985.

JONES, G.V.; DAVIS, R.E. Climate influences on grapevine phenology, grape composition, and wine production and quality for Bourdeaux, France. American Journal of Enology and Viticulture, Davis, v.51, n.3, p.249-261, 2000.

KISHINO, A.Y.; MARUR, I.P.H. Fatores climáticos e o desenvolvimento da videira. In: KISHINO, A. Y.; CARVALHO, S.L.C.; ROBERTO, S. R. Viticultura tropical. Londrina: IAPAR, 2007. p. 59-86.
KISHINO, A.Y.; ROBERTO, S.R. Tratos Culturais. In: KISHINO, A. Y.; CARVALHO, S.L. C.; ROBERTO, S. R. Viticultura tropical. Londrina: IAPAR, 2007. p. 171-202.

KUHN, G.B.; LOVATEL, J.L.; PREZOTTO, O.P.; RIVALDO, O. F.; MANDELI, F.; SÔNEGO, O. R. $O$ cultivo da videira: informações básicas. 2.ed. Bento Gonçalves: EMBRAPA-CNPUV, 1996. 60p. (Circular Técnica, 10).

LEÃO, P.C.S.; SILVA, E.E.G. Caracterização fenológica e requerimento térmico de variedades de uvas sem sementes no vale de São Francisco. Revista Brasileira de Fruticultura, Jaboticabal, v. 25, n. 3 , p. 379-382, 2003.

LEÃO, P.C.S.; SOARES, J.M.; RODRIGUES, B.L. In: SOARES, J.M.; LEÃO, P.C.S. A Vitivinicultura no Semiárido Brasileiro. Brasília: Embrapa Informação Tecnológica; Petrolina: Embrapa Semiárido, 2009. p. 151-214.

LIMA, M.A.C.; LEÃO, P.C.S.; RIBEIRO, A.P.L.; TRINDADE, D.C.G. Maturação de cultivares de uva nas condições do submédio São Francisco. In: CONGRESSO BRASILEIRO DE VITICULTURA E ENOLOGIA, 10., 2003, Bento Gonçalves. Anais... Bento Gonçalves: Embrapa Uva e Vinho, 2003. p. 196.

MANDELLI, F.; TONIETTO, J.; CAMARGO, U.A.; CZERMAINSKI, A.B.C. Fenologia e necessidades térmicas da videira na Serra Gaúcha. CONGRESSO BRASILEIRO DE FRUTICULTURA, 18., 2004, Florianópolis. Anais...CD-ROM.

MELLO, L.M.R. Perfil. Anuário brasileiro de uva e do vinho. Santa Cruz do Sul: Gazeta Santa Cruz, 2007. p. 40-77.

MENEZES, A.P. Vinhos e os determinantes da saúde - Dos fundamentos à Prática e à sociedade. In: SOUZA FILHO, J.M.; MOFROI, V. Vinho e saúde: vinho como alimento natural. Bento Gonçalves: Ibravin, 2005. p.13.

MOURA, M.S.B.; TEIXEIRA, A.H.C.; SOARES, J.M. Exigências climáticas. In: SOARES, J.M.; LEÃO, P.C.S. A Vitivinicultura no semiárido brasileiro. Brasília: Embrapa Informação Tecnológica; Petrolina: Embrapa Semiárido, 2009. p. 35-70. 
MURISIER, F.; ZIEGLER, R. Effects de la charge en bourgeons et de la densité de plantation sur le potentiel de production, sur la qualité du raisin et sur le développement végétatif. Revue Suisse de Viticulture, Arboriculture et Horticulture, Nyon, v.23, p.277-282, 1991. (não consta no texto)

MURAKAMI, K.R.N.; CARVALHO, A.J.C.; CEREJA, B.S.; BARROS, J.C.S.M.; MARINHO, C.S. Caracterização fenológica da videira cv. Itália (Vitis vinifera L.) sob diferentes épocas de poda na região norte do Estado do Rio de Janeiro. Revista Brasileira de Fruticultura, Jaboticabal, v.24, n.3, p.615-617, 2002.

RIZZON, L. A.; MIELE, A. Avaliação da cv. Cabernet Sauvignon para elaboração de vinho tinto. Ciência e Tecnologia de Alimentos, Campinas, v.22, n.2, p.192-198, 2002.

RIZZON, L. A.; MIELE, A. Avaliação da cv. Tannat para elaboração de vinho tinto. Ciência Tecnologia Alimentos, Campinas, v. 4, n. 2, p. 223-229, 2004.
RIZZON, L. A.; MIELE, A.; MENEGUZZO, J. Avaliação da uva cv. Isabel para elaboração de vinho tinto. Ciência Tecnologia de Alimentos, Campinas, v.20, n.1, p.115-121, 2000.

RUFFNER, H.P.; BREM,S.; MALIPIERO,U. The physiology of acid metabolism in grape berry ripening. Acta Horticuculturae, The Hague, n. 139, p.123-128, 1983.

SANTOS, C.E.; ROBERTO, S.R.; SATO, A. J.; JUBILEU, B. S. Caracterização da fenologia e da demanda térmica das videiras 'Cabernet Sauvignon' e 'Tannat' para a região norte do Paraná. Acta Scientiarum, Maringá, v.29, n.3, p.361-366, 2007.

SOUZA, C.M.; REGINA, M.A.; PEREIRA, G.E.; FREITAS, G.F. Indicação de cultivares de videira para o sul de Minas Gerais. In: REGINA, M. A. et al. (Ed.). Viticultura e enologia: atualizando conceitos. Andradas: Epamig-CECD, 2002. p.277-286. 